\title{
Comment on "A Global Map of Human Impact on Marine Ecosystems"
}

\section{Michael R. Heath}

Halpern et al. (Reports, 15 February 2008, p. 948) integrated spatial data on 17 drivers of change in the oceans to map the global distribution of human impact. Although fishery catches are a dominant driver, the data reflect activity while impacts occur at different space and time scales. Failure to account for this spatial disconnection could lead to potentially misleading conclusions.

A s spatial planning and legislation, which has long been applied to human activity on land, extends out into the marine environment, the need for a synthesis of the human impacts on the seas and oceans becomes ever more urgent. Thus, the initiative reported by Halpern et al. (1) is extremely timely and welcome. However, the task is a formidable

Fisheries Research Services, Marine Laboratory, 375 Victoria Road, Aberdeen AB11 9DB, UK. E-mail: heathmr@marlab.ac.uk one, and the results highlight some of the challenges that still need to be overcome.

Halpern et al. (1) estimated impacts on the oceans from a range of human activities, including various methods of fishing that are among the most important factors affecting the ecological state of many large marine ecosystems $(2,3)$. Spatial disaggregations $\left(1 / 2^{\circ}\right.$ latitude by $1 / 2^{\circ}$ longitude) of 1999 to 2003 regional landings data from the United Nations Food and Agriculture Organization (FAO) (4) were used as measures of fishing activity. Spatial disaggre- gation was performed by the Sea Around Us Project [SAUP (5)] on the basis of various covariates of fish distribution (temperature, depth, and primary production), together with a rulebased system defining the cells accessible to national fishing fleets (6). The ecological pressure caused by fisheries was assumed to be confined to catch locations, and the intensity was measured by dividing the catch density of landed fish (tonnes $\mathrm{km}^{-2}$ in $1 \mathrm{~km}$ by $1 \mathrm{~km}$ cells) by estimates of annual primary production (PP) derived from satellite remote sensing (7). The logic was that higher catch rates in lower productivity areas of the ocean should have a higher impact than similar catch rates in higher productivity areas. Location-specific vulnerability scores were then applied to translate activity measures into impacts.

One may worry about the precision with which the SAUP disaggregation method represents the spatial distributions of where the fish landed from a region were actually caught $(8)$ but, regardless of any such concerns, the key problem is that the spatial footprint of the impacts may differ from the distribution of catches and affect different ecosystems from those in which the catching activity occurred. Clearly,

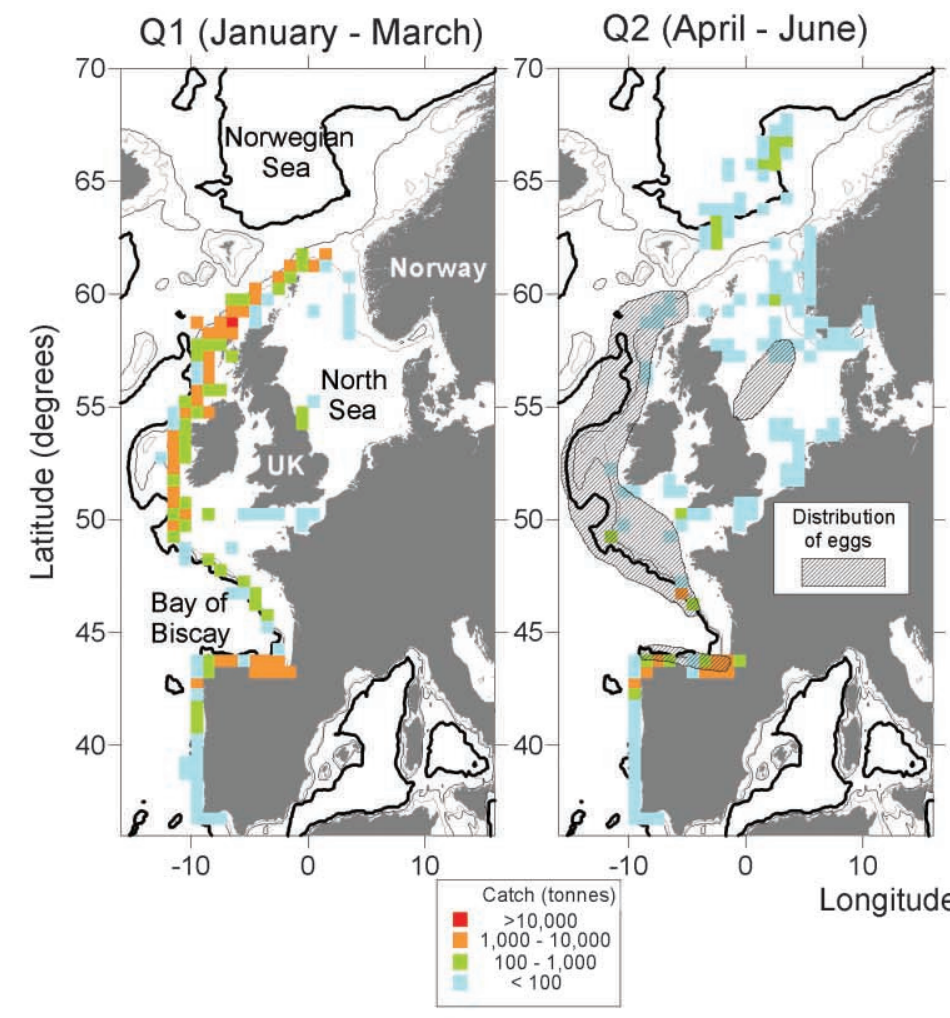

\section{Q3 (July - September) Q4 (October - December)}
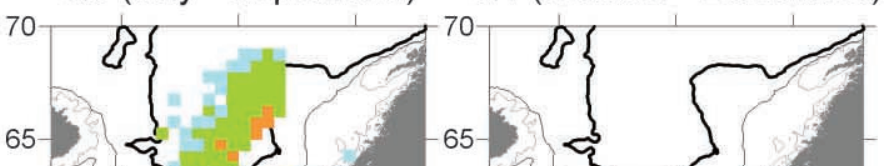

Fig. 1. Quarterly distributions $\left(12^{\circ}\right.$ latitude by $1^{\circ}$ longitude) of catches from the northeast Atlantic mackerel stock for 2006 [data from (14)]. Total annual catch was 472,700 tonnes, exceeded in the northeast Atlantic only by catches of Norwegian Sea herring. Surveys of planktonic eggs show that the majority of spawning activity occurs in Q2 west and southwest of Ireland $(14,15)$. Tagging studies (16) show that after spawning, the majority of fish migrate $\sim 2000 \mathrm{~km}$ northward into the Norwegian Sea to feed during Q3, with a southward return migration during Q4 and Q1. The stock is only lightly

exploited during Q2 when fish are close to the sea surface and difficult to catch. Most of the catch is taken during Q4 and Q1 when the fish are aggregated into very large schools. In 2006, 300,000 tonnes (63\% of the annual total) were taken from an area of $\sim 5000 \mathrm{~km}^{2}$ off the northern United Kingdom. Although there must be local impacts due to bycatch and slippage from nets ( $\sim \%$ of catch), the principal ecological impacts on an annual time scale must be distributed over the spatial envelope of the stock as a whole, which exceeds $250,000 \mathrm{~km}^{2}$. 
the physically destructive impacts of certain fishing gear and some of the impacts of discarded bycatch occur local to the activity. However, other major ecological consequences occur at locations far removed in space and time from catches, depending on the biology and migratory behavior of the species concerned. Almost all open water pelagic and demersal fish exhibit spatial and ecosystem segregation of life stages (larvae, juveniles, and adults) over scales ranging from tens to thousands of kilometers, with lifecycle connectivity through active migration by juveniles and adults and passive transport of eggs and larvae by ocean currents. In contrast, fisheries are generally targeted at the most commercially valuable life stages, which are usually the adults. Removal of mature fish affects the supply of juveniles elsewhere in the system, with consequences for species richness and diversity, marine predator populations, and food web functionality $(9-11)$ that extend over a far greater area and range of ecosystems than the fishing activity itself.

The northeast Atlantic mackerel fishery (Fig. 1) provides an illustration of the generic problem. Most of the food consumption by mackerel caught around the north of the United Kingdom occurs $\sim 1000 \mathrm{~km}$ away in the Norwegian Sea rather than in the locality of the catches, whereas the consequences of removing mature adults will be realized far to the south in the spawning area and in inshore waters that form the habitat for juvenile offspring. Hence, the impact of the mack- erel fishery is too localized in the analysis of Halpern et al., leading to exaggeration of the cumulative human impact on waters around the northern United Kingdom.

Incorporating the spatial disconnect between fishing activity and its ecological impact into integrated assessments could be done at a regional scale for some species using spatially resolved population demography models (12) to diagnose the spatial impact of a given pattern of catches. However, more generally, there needs to be some consideration of the spatial graininess at which it is meaningful to represent the impact of fisheries on marine ecosystems, given the oceanography of a region and the biology of species inhabiting it.

Halpern et al. (1) have assembled global data on human activity in the oceans, which is an achievement in itself, and initiated a diagnosis of cumulative impact. However, it is clear that more needs to be done to realistically equate the spatial characteristics of activity to impact, especially in the case of fisheries. Although activity can, theoretically, be resolved to fine geographic scales, there are serious scientific issues regarding the threshold of graininess below which assessments of impact are legitimate.

\section{References and Notes}

1. B. S. Halpern et al., Science 319, 948 (2008)

2. S. Jennings, M. J. Kaiser, Adv. Mar. Biol. 34, 201 (1998).

3. S. J. Hall, The Effects of Fishing on Marine Ecosystems and Communities (Blackwell Science, Oxford, 1999).
4. Food and Agriculture Organization, FishStat Plus: Universal software for fishery statistical time series; www.fao.org/fishery/topic/16073.

5. The Sea Around Us Project, University of British Columbia, www.seaaroundus.org.

6. R. Watson, A. Gelchu, D. Pauly, in Fisheries Impact on North Atlantic Marine Ecosystems: Catch, Effort and National and Regional Data Sets, D. Zeller, R. Watson, D. Pauly, Eds.. Fisheries Centre Research Reports 9 (2001), pp. 1-11.

7. M. J. Behrenfeld, P. G. Falkowski, Limnol. Oceanogr. 42, 1 (1997).

8. The SAUP methodology (6) disaggregates regional annual fishery landings to $1 / 2^{\circ}$ spatial resolution. This is a bold attempt at a difficult task and there will always be discrepancies from reality, so the results should be used with caution. For example, the SAUP estimate of the spatial distribution of Atlantic mackerel catches since 2000 (13) fails to reflect the annually recurrent component of the fishery that occurs in the Norwegian Sea and misrepresents the distribution of catches from the northern North Sea.

9. S. P. R. Greenstreet, S. I. Rogers, ICES J. Mar. Sci. 63, 573 (2006).

10. B. Worm et al., Science 314, 787 (2006).

11. M. Frederiksen et al., J. Appl. Ecol. 41, 1129 (2004).

12. J. M. Andrews et al., Can. J. Fish. Aquat. Sci. 63, 1027 (2006).

13. SAUP, Marine catches of Atlantic mackerel: 1950-2003, www.seaaroundus.org/mapviewer/viewer.htm? Taxonkey $=600118 \&$ Taxa $=$ Atlantic $\% 20$ mackerel $\&$ Class $=3$.

14. International Council for the Exploration of the Sea, Report of the Working Group on the Assessment of Mackerel, Horse Mackerel, Sardine and Anchovy (WGMHSA) (ICES CM 2007/ACFM:31); www.ices.dk/ reports/ACOM/2007/WGMHSA/WGMHSA07.pdf.

15. D. ]. Beare, D. G. Reid, ICES J. Mar. SCi. 59, 711 (2002).

16. A. Uriarte, P. Lucio, Fish. Res. 50, 129 (2001). 